\title{
Results of the European thematic network ageing and disability: improving the quality of life of elderly persons through more physical activity
}

\author{
Herman Van Coppenolle - S. Djobova • A. Niemiro • \\ I. Dobreva • K. U. Leuven
}

Received: 11 August 2010 /Accepted: 11 August 2010/Published online: 21 August 2010

(C) European Group for Research into Elderly and Physical Activity (EGREPA) 2010

\begin{abstract}
Experts in Adapted Physical Activity (APA) for elderly persons from 66 higher education institutions of 29 European countries worked during 3 years together (20042007) in producing education materials to promote an active lifestyle, the content of an APA programme for the elderly at master and bachelor level, a motivational DVD (Never too old to be Active: The Joy of Movement and practical active ageing activity cards and a brochure with a European survey and recommendations. During the dissemination year (2009-2010) these materials were translated from English into 15 European languages and disseminated in all countries in institutions of Higher Education (physical education, physiotherapy, sport science), nursing homes for elderly persons and caregivers). In each country, as many as possible elderly persons were approached as well as the concerned ministries, sports organizations and the press. A consortium was created between the universities of Amiens (France), Groningen (The Netherlands) and Verona (Italy), to start up the European Masters programme in APA for the elderly and the motivating products disseminated the urgent message of the Thematic Network for all elderly persons with and without disabilities in Europe "Save yourself by more physical activity" This same approach applied in all European countries at the same time during these 4 years,
\end{abstract}

H. Van Coppenolle $(\bowtie) \cdot$ S. Djobova $\cdot$ A. Niemiro $\cdot$ I. Dobreva

K. U. Leuven

Faculty of Kinesiology and Rehabilitation Sciences,

Tervuursevest 101,

BE-3001 Heverlee, Belgium

e-mail: herman.vancoppenolle@faber.kuleuven.be

URL: www.thenapa2.org gave a boost to the better education of students in this matter: stimulating the responsibility and motivation of elderly persons for bringing more physical activity in their daily schedule, during at least $30 \mathrm{~min}$ each day. The established cooperation between the actors of the network should however be continued through the European Master in APA for the elderly and further dissemination of the products through the website www.thenapa2.org

Keywords Adapted physical activity - Elderly persons · Quality of life · European cooperation

\section{Introduction and methodology}

From 2004 to 2007, 40 experts in Adapted Physical Activity (APA) for elderly persons with and without disabilities from 29 European countries worked together in the European Thematic Network funded by the European Commission "Ageing and disability - a new crossing between physical activity, social inclusion and life-long well-being", called Thenapa 2.

They met in total seven times during 3 days in different locations: Malta, Lithuania, Cyprus, Romania, Italy, Germany and Austria.

They wanted to bring more attention to this actual problem in all European countries: trying to improve by more physical activity the quality of life of elderly persons with and without disabilities. Nearly $37 \%$ of the European population will be aged 60 years or more in 2050, and research proved that without any doubt more physical activity increases in a significant way the quality of life of these persons. So the conclusion is clear. We must prepare better qualified professionals in this field now, in order to 
meet the new demands of the future. The concrete objectives of the Network were:

- Provide a better Education of Professionals in Adapted Physical Activity for the Elderly on Master and Bachelor level

- Produce concrete "products" to stimulate more physical activity and disseminate them in all countries

\section{Results}

1. Better Education for professionals at master and bachelor level

The European Curriculum for a Master course on Ageing and Disability was developed which further on was produced in the form of a CD-ROM as part of the e-learning objectives of the project. The curriculum gives detailed description of the modules and subjects that should be taught in the European Master in APA for the elderly. It includes the aims and the objectives of the whole course and of the specific modules, duration of the programme, ECTS credits and examples of subject literature. It also provides a separate module on the subject of Ageing and disability which can be easily integrated in the current student's curriculum on bachelor level in the related academic disciplines (physiotherapy, physical education, kinesiology, occupational therapy, social workers, nurses, etc.). The CD-ROM is available in English. European Curriculum for a Master course on Ageing and Disability.

The universities of Amiens (France), Groningen (The Netherlands) and Verona (Italy) will shortly start up the implementation of the European Master programme in Adapted Physical Activity for the Elderly.

2. Realisation of concrete products for stimulation of more physical activity for elderly persons:

a. Three educational/motivational movies were produced in the form of a DVD. They present examples of best practices in the area of APA for elderly. Each movie shows activities performed by elderly and disabled and not disabled persons in three main settings: outdoor activities, indoor activities and water activities. The DVD is available in 18 European languages (English, French, German, Bulgarian, Czech, Dutch, Estonian, Finish, Greek, Italian, Latvian, Lithuanian, Polish, Portuguese, Romanian, Slovak, Slovenian and Spanish).

b. Resource cards "Active Ageing Activity Cards" for instructors: They present examples of easy to perform activities that can be beneficial for elderly with different disabilities. Each card contains the name and the explanation of the activity, its main goal, materials needed to perform it, safety considerations, possible adaptations according to the performance level of the participants, and ideas to make the game/activity more attractive.

c. A comparative study on European level "The current European situation on ageing and disability" was made, which led to the construction of a summary on the topic, which finally resulted in developing the THENAPA II brochure of recommendationsrealised by the network partners, experts in the area of APA for the elderly. The recommendation are giving directions on what is done and what is needed to be done in the academic, social and individual level in the field of APA for elderly. The THENAPA II recommendations are available in English as well as in most other European languages.

d. Results of the Dissemination: Impact report. The detailed results of the global impact of these Thenapa 2 products and activities in all included countries are given in detail in our website. Thenapa II Dissemination-IMPACT REPORT

\section{Conclusion}

We were very enthusiastic about our products and dissemination effects in all European countries and will continue to disseminate the message of trying to make elderly persons more physical active by daily physical activities having a fixed place in their agenda for which they are motivated. Because without motivation they will not continue their daily movement activities programme. These movement activities should make them "addicted" to them and provide them a daily kind of "movement orgasm" which will motivate them to never give up and will provide them a better quality of life. 